\title{
МЕТАФОРИЧЕСКИЕ АППОЗИТИВНЫЕ СЛОВОСОЧЕТАНИЯ С ЛИЧНЫМ ЗНАЧЕНИЕМ В ТЕКСТАХ СОВРЕМЕННОЙ РУССКОЙ ПРЕССЫ
}

\author{
METAPHORICAL APPOSITIVE PERSONAL PHRASES \\ IN THE CONTEMPORARY RUSSIAN PRESS
}

\author{
ПАУЛИНА МУРАВСКА
}

\begin{abstract}
This article is devoted to studying metaphorical appositive asyndetic phrases in the language of the Russian press. The author presents a variety of aspects related to the semantic characteristics of metaphorical, appositive asyndetic phrases and aims to define the importance of these language units for sociolinguistic and psycholinguistic analysis.

Paulina Murawska, Uniwersytet im. Adama Mickiewicza w Poznaniu, Poznań - Polska.
\end{abstract}

Язык СМИ, как элемент публичной коммуникации, привлекает внимание исследователей прежде всего благодаря тому, что „наглядно отражает движение языковой материи, чутко реагирует на изменение социальных и генерационных пропорций в обществе [...]"1. Наблюдение за симптомами новых тенденций в языке современной прессы имеет большое значение, так как именно они могут в дальнейшем предопределять характер развития номинационного процесса 2 .

Публицистические тексты представляют собой практически неисчерпаемый источник новых средств номинации - как конвенциональных, которые входят в состав языковой системы, так и неконвенциональных, которые остаются в зоне единиц текста ${ }^{3}$ Как замечает С. Ле-

${ }^{1}$ Г.П. Н е щ и м е н к о, Активизация использования словообразования в языке публичной коммуникации в конце столетия, [в:] Stowotwórstwo a inne sposoby nominacji. Materiaty z 4 konferencji Komisji Stowotwórstwa przy Międzynarodowym Komitecie Slawistów. Katowice 27-29 września 2000 r., pod red. K. Kleszczowej i L. Selimskiego, Katowice 2000, c. 70 .

2 Там же.

${ }^{3}$ Н.В. И с а е в а, Новые наименования миц на рынке труда (структурно-семантический и функциональный апсекты. Автореф. дисс. ...канд. филол. наук, Москва 2010, c. 8 . 
щак, исключительный характер номинатов в этой сфере языка обусловливается их узкоситуативным и глубоко личностным характером4.

М.А. Сухопарова подчеркивает, что в номинативной сфере языка прессы особое место занимают свободно создаваемые авторами аппозитивные словосочетания типа женщина-икатулка, камень-шпион, щиmы-книжки и др. ${ }^{5}$ По мнению ученой, высокая продуктивность единиц данного типа в публицистических текстах связана с тем фактором, что краткость, компактность формы сочетается в них с емкостью и сложностью семантики.

В данном контексте особого внимания заслуживают аппозитивные словосочетания с метафорическим значением типа женщина-весна, мужчина-мечта, человек-автомат. Выражая полное согласие с авторами книги Метафоры, которыми мы живем, мы считаем, что любая метафора, как конвенциональная, так и неконвенциональная, представляет собой намного болыше, чем лишь стилистический прием. С точки зрения говорящих метафоры являются центральным элементом языка, влияющим на способ восприятия и мышления, на предпринимаемые человеком действия 6 . Конвенциональные метафоры как элементы общепонимаемого участниками процесса общения кода структурируют нашу повседневную деятельность ${ }^{7}$, тогда как неконвенциональные, возникшие в результате творческой лингвокреативной деятельности человека, открывают путь к новому пониманию человеческого опыта8.

На наш взгляд, аппозитивные словосочетания метафорического характера заслуживают особого внимания прежде всего балгодаря скрывающемуся в них метафорическому потенциалу слов-компонентов, стимулирующему человека к использованию лингвокреативных способностей. Выход за рамки системных отношений между словами, их неконвенциональное сочетание, дает интересные, особенно с когнитивной точки зрения, эффекты. Именно в таких словосочетаниях четко проявляется способность лексических единиц к различного рода семантическим трансформациям.

${ }^{4}$ С. Л е щ а к, Языковое клише: прагматика, семантика и структура аналитических номинативных неидиоматических знаков в современном русском языке, [в:] электронный pecypc: www.ujk.edu.pl/ leszczak/jazklisze.doc (19.06.2012).

5 М.А. С у х о п а р о в а, Составные наименования в современном русском языке (на материале периодически газетных издании), „Вестник Московского государственного областного университета. Сер.: Русская филология”, Москва 2008, № 3, с. 131.

6 Дж. Л а к о ф ф, М. Д ж о н с о н, Метафоры, которыми мы живем, Москва 2004, c. 25 .

7 Там же, с. 26.

8 Там же, с. 169. 
В настоящей статье нам хотелось бы обратить внимание на метафорические аппозитивные словосочетания (дальше: МАС) с личным значением типа человек-мозг, человек-домкрат, человек-миссия. В структуре изучаемых единиц компонент, традиционно не соотносимый с семантическим классом названий лиц, служит спецификации значения МАС, являясь носителем его основного смысла, в то время как компонент, называющий человека, способствует восприятию метафорической конструкции как названия лица. Данное положение наглядно отражается в контекстах:

Человек-мозг - таинственный мужчина с выдающейся памятью, высоким интеллектом и идеальным телом, но, кажется, он не испытывает обычных человеческих эмоций (http://www.kinopoisk.ru/film/689035/);

„Человек-домкрат” (подзаголовок) С 8 сентября на Пушкинской площади столицы среди праздно шатающегося народа надрывается 43-летний силач Владимир Савельев („Комсомольская правда”, 2004.09.17);

Киссинджер с тех пор, как в конце 60-х годов он в качестве протеже Нельсона Рокфеллера был введен из академической среды в большую политику, - не просто один из членов глобальной элиты (член Совета по внешней политике, Бильдербергского клуба, Трехсторонней комиссии и прочая и прочая), но своего рода человек-миссия, выступлениями которого принято обозначать смену вех (РИА „Новости”, 2005.06.16).

МАС человек-мозг представляет собой наименование человека, лишенного эмоций и обладающего высокими умственными способностями. Употреблению лексемы мозг в данном контексте способствует ее значение, зафиксированное в ТСШ': 'центральный отдел нервной системы человека и животных - нервная ткань, заполняющая череп и канал позвоночника; орган высшей нервной деятельности' и 'nерен. ум, умственные способности (разг.)'. Здесь можно говорить об использовании приема синекдохизации, т. е. такого вида метонимизации, в котором название какого-то определенного элемента (мозг) избирается говорящим в качестве замены обозначения целого ${ }^{10}$ (выдающаяся память, высокий интелект, игнорирование эмоций). С психолингвистической точки зрения выбор какого-то элемента для замены обозначения целого обусловливается именно тем, на каком аспекте целого сфокусировалось внимание говорящего ${ }^{11}$. Подбор слова мозг как компонента МАС служит тому, чтобы подчеркнуть отличительные интеллектуальные способности, органом отвечающим за которые является именно человеческий мозг. Тем самым компонент мозг является мето-

${ }_{9}^{9}$ С.И. О же е г о в, Н.Ю. Ш в е д о в а, Толковый словарь русского языка, Москва 2003.

10 Дж. Л а к о ф ф, М. Д ж о н с о н, указ. соч., с. 61.

11 Там же, с. 62. 
нимическим репрезентантом интеллектуальных качеств, а вся конструкция человек-мозг представляет собой метафору: человек - это мозг.

В МАС человек-домкрат раскрывается коннотативный потенциал слова домкрат как обозначения огромной физической силы (ср. ТСШ 'домкрат - механизм для подъема тяжестей на небольшую высоту'). В качестве слова-стимула, позволяющего точно понять значение данного МАС, появляется слово силач, которое в данном контексте является синонимом словосочетания человек-домкрат. Тем самым здесь тоже можно говорить о приеме метонимизации. В данном словосочетании компонент домкрат, т. е. название машины определенного типа, заменяет название абстрактного понятия физической силы. В семантической структуре МАС человек-домкрат также содержится метафора: человек - это домкрат.

Похожим образом организована семантическая структура МАС человек-миссия, в котором компонент миссия является метонимией способности человека к выполнению ответственных заданий дипломатического характера, что совпадает с совокупностью значений слова миссия в ТСЕ12: 'ответственная роль, задание, поручение', 'дипломатическое представительство, возглавляемое посланником или поверенным в делах'. Тем самым МАС человек-миссия обозначает человека, способного успешно выполнять ответственные дипломатические задания и поручения, т. е. содержит в своей смысловой структуре метафору: человек - это миссия.

Следует, однако, подчеркнуть, что в свободно создаваемых в текстах МАС процесс активизации разных аспектов значений одного и того же лексического компонента и тем самым модификация значения данного словосочетания как цельной единицы текстовой номинации не обусловливаются лишь семантической структурой слов-компонентов. Одна и та же лексическая единица, будучи компонентом МАС, может выполнять в его внутренней смысловой структуре разные функции, т. е. может участвовать в образовании МАС с разной семантикой. Данный факт мы представим на примере трех словосочетаний, в которых появляется компонент мечта, однако в каждом из них он является метонимическим выражением разных (хотя, правда, близких по значению) смыслов:

А в женщину-мечту ее превращает коктейль из внешности, здоровья, славы и многомиллионных гонораров („Труд-7", 2010.07.27);

„КРЕМЛЕВСКИЙ МУЖЧИНА-МЕЧТА” (подзаголовок): Кстати, Зумруд как-то призналась, что Аркадий - мужчина ее мечты („Труд-7”, 2007.09.20);

12 Новый словарь русского языка: толково-словообразовательный, т. 1, под ред. Т.Ф. Ефремовой, Москва 2000. 
Для меня Паганини - человек-мечта, с детства и до сих пор я пытаюсь разгадать его загадку. [...] Это была совершенно мистическая фигура.” („Труд-7”, 2001.09.28)

В первом контексте компонент мечта передает значение 'тот, чьи мечты сбываются, кто живет жизнью, о которой мечтают другие люди', о чем свидетельствует наличие таких слов-стимулов, как здоровье, слава, многомилионные гонорары. Во втором примере в высказывании появляется выражение, являющееся синонимом МАС мужчина-мечта и, тем самым, раскрывающее его смысл: мужчина-мечта - это „мужчина ее мечmы". Стоит отметить, что в данном контексте слово мечта проявляет тесную связь со своим прямым значением: 'мечта - предмет желаний, стремлений' (ТСШ). В третьем контексте также находится выражение, раскрывающее смысл МАС человек мечта, - „мистическая фигура". Тем самым можно полагать, что единица человек-мечта является синонимом слова мечтатель (ср. значения слов мечтатель, мистика и мистик в ТСЕ). Из этого явно вытекает, что в МАС женщина-мечта, мужчина-мечmа и человек-мечта выбор конкретного аспекта значения, которое хотел добыть на поверхность автор, мотивируется и одновременно объясняется контекстом высказывания и накопившимися в нем словами-стимулами.

Анализируя МАС с личным значением в текстах современной русской прессы, мы обнаружили, что единицы данного типа служат, прежде всего, либо физической и физиологической, либо морально-психической характеристике лищ.

К первой группе можно отнести различные единицы, именующие человека по внешнему сходству с каким-нибудь объектом, напр. человек-гора, человек-медведь, мама-хомячок, подружка-ватрушка, старушка-одуванчик, женшина-зима и др. МАС человек-гора и человек-медведь указывают на крепкое телосложение, что дополнительно подтверждают появившиеся в контекстах выражения (не) смог бы обхватить его двумя руками, гигант и большой:

Не уверен, смог бы обхватить его двумя руками. Это настоящий человек-гоpa. Я играл против греческого гиганта Софоклиса Скорцианитиса - так того с места нельзя было сдвинуть („Советский спорт”, 2010.11.01);

Но вот мой дедушка - он всегда был и остается этаким большим человеком-медведем („Труд-7”, 2010.12.27).

MAC подружка-ватрушка и мама-хомячок также содержат в себе характеристику человека по особенностям телосложения, однако акцент падает здесь на ожирение:

Подружка-ватрушка: на бедрах - ушки (http://www.hudeem-vmeste.ru/blog/ podruzhka-vatrushka-bedrakh-ushki/41264); 
Ирина показывает фотографию того времени, на которой стоит грустная, полная - 145 килограммов - женщина. [...] Благодаря одному психотропному препарату похудела на 22 кг. Сначала радовалась. А когда стали появляться галлюцинации, бросила. Решила, что Виталику важнее мама-хомячок, чем мама-шизофреник. Килограммы вернулись („Комсомольская правда”, 2011.05.12).

МАC старушка-одуванчик опирается на ассоциацию цвета и фактуры волос пожилой женщины с одуванчиком, а также имеет свои источники во фразеологизме божий одуванчик, обозначающем, по ТСШ, тихого и слабого, обычно пожилого человека:

Но все терпеливо ждут: беременные женщины, старушки-одуванчики, мамы с маленькими детьми, солидные бизнесмены („Комсомольская правда”, 2007.04.26).

MAC женщина-зима называет женщину по характерному для нее цветовому типу красоты. В статьях для женщин, посвященных правилам подбора одежды и макияжа, цветовые типы женской красоты часто соотносят именно с временами года:

Макияж: женщина-,,зима" яркая от природы, поэтому может обходиться минимумом косметики („Комсомольская правда”, 2007.09.05).

К семантической группе МАС, характеризующих человека по его физическим и физиологическим признакам, можно также отнести единицы, именующие лиц по разовым или характерным физическим действиям, напр. по способу передвижения:

Девушка-кошка так вышагивала, лишь изредка приподнимая шторки ресниц, за которыми танцевали язычки настоящего, взрослого, а отнюдь не пионерского пламени, что мужская половина аудитории тут же отреагировала протяжным: „О-о-о-о!!!” („Комсомольская правда”, 2002.11.19);

Так плавают дельфины. [...] Теперь грузинский "человек-дельфин" готов штурмовать „по-колхски" пролив Ла-Манш („Комсомольская правда”, 2002.09.07).

К примерам таких единиц можно отнести также МАС человек-молот и человек-машина, характеризующие способ совершения физического действия:

Боснийский „человек-молот" прославился своим предыдущим рекордом - в прошлом году за минуту он раздавил 65 пивных банок („Известия”, 2009.09.29);

А для людей, представляющих Валуева как человека-машину, который „пришел, ударил и победил”, его текст „вообще станет откровением” - признается Осипов („Труд-7”, 2007.02.23).

Как было нами сказано раньше, МАС с личным значением являются удобным средством не только физической, но также и морально- 
-психической характеристики человека. К единицам, характеризующим лищ по ассоциируемым с каким-нибудь объектом или понятием нравственным характеристикам, можно отнести МАС, называющие человека по положительному умонастроению, энергичности, напр. дeвушка-солнышко, женшина-весна, человек-батарейка и человек-зажигалка:

И это говорила улыбчивая Алина, девушка-солнышко?! („Комсомольская правда", 2002.11.22);

„Женщина-весна" (подзаголовок): Мое душевное состояние всегда радостное и весеннее („Комсомольская правда”, 2002.11.13);

Семак, мне кажется, единственный в своем роде в России. Человек-батарейка. Это настоящий энергетический центр и при этом интересный, позитивный человек („Советский спорт”, 2011.01.22);

Станьте балагуром Парадокс, но коллектив простит вам лень и „спихивание” ваших задач на других, если вы луч света, человек-зажигалка и главный хохмач коллектива („Труд-7”, 2009.02.11).

Характеристику человека по способу мышления и рассуждения, по умственным способностям содержат такие МАС, как женщина-булкан и человек-компьютер:

Она женщина-вулкан: копит, копит, а потом извергает новые проекты („Комсомольская правда", 2006.10.09);

В 1995 году пенсионерка Вера Витальевна Рощина из Волгограда после болезни сердца не только обнаружила тягу к всевозможным языкам, но и невероятные способности к быстрому счету, став чуть ли не человеком-компьютером („Комсомольская правда”, 2005.06.05).

По уровню знаний называют человека МАС человек-оркестр и человек-энциклопедия:

При этом фактически работают всего 19 „человек-оркестров”, вынужденных разбираться в совершенно разных отраслях (РБК Daily, 2011.03.02);

Другой интеллигентнейший представитель еще более ранней тренерской плеяды Николай Старостин. Человек-энциклопедия, кладезь знаний. Любимец многих футбольных поколений („Труд-7”, 2006.06.09).

В собранном материале мы обнаружили также примеры единиц, называющих человека по авторитету и значительности, напр. женщина-стиль, женщина-эпоха, человек-бренд:

Рената Литвинова - уже сама по себе женщина-стиль. Когда-то стилисты и визажисты делали ей замечания: мол, и красится-то неправильно, и гардероб подбирает так себе. А в конце концов все дружно присвоили ей звание самой стильной актрисы российского кинематографа („Комсомольская правда", 2003.08.05); 
Завтра легендарный композитор отмечает день рождения. Она - женщина-эпоха, наверное, единственная, кого можно назвать народным композитором страны („Комсомольская правда”, 2009.11.08);

Баков - человек-бренд на рынке политконсалтинга: в его распоряжении есть и одна из самых крупных в стране сетей агитаторов, и люди, отвечающие за разработку стратегии, и группа технологов, выдумывающая слоганы и события кампании („Новый регион 2”, 2007.10.02).

По отсутствию авторитета или значительности называют человека такие МАС, как девушка-пустышка и человек-этикетка:

Девушка-пустышка. Никакой оригинальности, полное отсутствие вкуса при довольно сносных внешних данных и хорошенькой фигурке („Комсомольская правда", 2001.11.16);

Реальным вождем их остался Басаев. Но ставка исключительно на террор означает потерю политической поддержки Запада. Поэтому Басаеву остро необходим человек, не запачканный по горло кровью, человек-этикетка („Комсомольская правда", 2005.03.09).

Любопытно отметить, что между МАС человек-бренд и человек-этикетка, появившимися в статьях разных авторов, в разных газетах, можно обнаружить антонимические отношения. Слово бренд, соотносимое с торговой маркой, вызывает положительные ассоциации, участвуя в образовании МАС с мелиоративной оценкой нравственных качеств человека, тогда как слово этикетка, обозначающее 'ярлычок с фабричным торговым клеймом, надписью' (ТСШ), является компонентом МАС с пейоративным значением.

Кроме физических и моральных особенностей, МАС могут называть человека и по другим характеристикам. В собранном нами материале нашлись контексты, в которых структура МАС использовалась для характеристики человека по области профессиональной деятельности:

В относительно более выгодном положении окажутся специалисты с высшим образованием, относящиеся к профессиям типа „человек-техника” (инженеры, технологи, конструкторы, проектировщики, программисты) и „человек-природа" (агрономы, зоотехники, врачи) („Труд-7”, 2009.06.24);

Женщина-мюзикл Лайза Миннелли, необыкновенное сопрано Виолетта Урмана, танцевальная авангардистка Ройзин Мерфи - три выдающихся артистки приезжают на этой неделе с концертами в Москву, три разных жизненных пути сходятся в одной географической точке („ТТуд-7”, 2008.05.22).

Структура МАС неоднократно используется также для передачи значения 'человек в какой-то маскарадной одежде, переодетый чем-то или кем-то': 
Мгновенно войдя в роль, девушка-колокольчик заговорила низким грудным голосом и сообщила: „Осторожно, двери закрываются” („Комсомольская правда", 2004.06.16);

В День влюбленных по Арбату бегал юноша-купидон в белых трусах и с картонными крыльями любви и опрыскивал парочки „аэрозолем” („Новая газета", 2004.03.15);

Костюм женщины-кошки, кокетливый халатик медсестры или платье с вишенками на бюсте - наряды эротического характера всегда пользуются спросом („Труд-7”, 2006.12.29).

Проведенный нами семантический анализ МАС с личным значением показывает, что единицы данного типа представляют собой удобное средство образования новых названий лиц-носителей признаков. Семантическая структура МАС опирается на схему метафоры, обнаруживающей сходство человека с каким-нибудь другим объектом материальной или духовной действительности. Причем компонент, называющий человека, является в МАС модификатором значения лишь в таком смысле, что несет информацию о личном значении данной конструкции, в то время как семантическим ядром МАС, носителем его основного смысла, является именно компонент с образно-переносным значением. Тем самым оба компонента МАС взаимодополняют друг друга и не могли бы существовать отдельно без изменения значения конструкции в целом, что является доказательством семантической цельности единиц данного типа, довлеющей над их двусловностью, структурной раздельнооформленностью.

МАС являются удобным инструментом для укладывания относительно больших долей смысла в краткие формы. Свертыванию больших кусков информации и смысла в компактную форму МАС способствует не только огромный семантический потенциал слов-компонентов, но также крепкая связь МАС с контекстом, материальным выражением которой являются различного рода слова-стимулы.

Структура МАС дает автору высказывания возможность собрать и подытожить рассеянные семы и активизировать их в сознании получателя коммуниката. Такая семантическая конденсация не только облегчает фиксацию и передачу результатов познавательного опыта от человека к человеку, но также помогает подчеркнуть именно те их элементы, которые являются самыми главными, самыми существенными. Причем возможности называть и одновременно характеризовать человека с помощью МАС ограничиваются лишь креативностью говорящих.

Вышеперечисленные черты делают МАС не только средством отражения результатов познавательного опыта носителей языка, но также удобным средством манипуляции общественным мнением. Указание 
общественных перемен, представление новых фактов в жизни общества и формирование оценки этих фактов у адресантов, в свою очередь, являются неоднократно приоритетной целью СМИ. Именно поэтому несомненно важным и актуальным вопросом мы считаем изучение МАС в языке современной прессы с учетом их социолингвистического и психолингвистического потенциала. 